\begin{tabular}{l|l|l}
\hline & $\begin{array}{l}\text { Proceedings of the } \\
\text { Informing Science }+\end{array}$ & $\begin{array}{l}\text { An Official Publication } \\
\text { of the Informing Science Institute } \\
\text { InformingScience.org }\end{array}$ \\
\hline
\end{tabular}

\title{
Explaining Performance Using A Multi-Media TOOL
}

\begin{tabular}{lll}
\hline Raafat Saadé* & $\begin{array}{l}\text { Concordia University, Montreal, } \\
\text { Canada }\end{array}$ & $\underline{\text { rafat.saade@,concordia.ca }}$ \\
Fassil Nebebe & $\begin{array}{l}\text { Concordia University, Montreal, } \\
\text { Canada }\end{array}$ & $\underline{\text { fassil.nebebe@,concordia.ca }}$ \\
Dennis Kira & $\begin{array}{l}\text { Concordia University, Montreal, } \\
\text { Canada }\end{array}$ & \\
$*$ dennis.kira@,concordia.ca
\end{tabular}

\section{ABstract}

Aim/Purpose

Multimedia has been accepted as an enhanced learning medium. We present in this paper the application of a multimedia tool to teach the entity relationship diagram and its effect on performance.

Background Based on the theory of flow and, more specifically, cognitive absorption and perceptions (usefulness and, ease of use, attitudes and intentions) we propose a model to explain performance after using a multimedia tool.

Methodology

A survey methodology approach was used. Structural equation modeling was performed to test the model hypotheses.

Contribution

Empirical work on the effects of multimedia on learning is relatively little and its effect on performance is not studied.

Findings

Impact of cognitive absorption on perceptions is strong and intentions play an important role in mediating the relationship between attitudes and performance.

Recommendations Need to consider flow by including competition and gaming into multimedia for Practitioners learning tools. Also, practitioners need to integrate leveling capabilities to the multimedia experience.

Recommendation Empirical studies on the impact of flow variables such as boredom, anxiety, for Researchers enthusiasm on performance.

Keywords multimedia, performance, cognitive absorption, flow, learning

Accepting Editor: Eli Cohen | Received: February 17, 2019 | Revised: March 7, 2019 |

Accepted: March 10, 2019.

Cite as: Saadé, R., Nebebe, F., \& Kira, D. (2019). Explaining performance using a multi-media tool. Proceedings of the Informing Science and Information Technology Education Conference, Jerusalem, Israel, pp. 307-319. Santa Rosa, CA: Informing Science Institute. https://doi.org/10.28945/4354

(CC BY-NC 4.0) This article is licensed to you under a Creative Commons Attribution-NonCommercial 4.0 International License. When you copy and redistribute this paper in full or in part, you need to provide proper attribution to it to ensure that others can later locate this work (and to ensure that others do not accuse you of plagiarism). You may (and we encourage you to) adapt, remix, transform, and build upon the material for any non-commercial purposes. This license does not permit you to use this material for commercial purposes. 


\section{INTRODUCTION}

Students today use social networks extensively for the management of their academic needs (Cheung, Pui-Yee, \& Lee, 2011). Such social networks, which include a large amount of multimedia resources, include Facebook, Twitter, YouTube, Flickr or Alibaba (Srivastava 2012; Teo \& Neo, 2006). Students consume these multimedia systems and even produce multimedia artifacts (e.g., recording videos with their smartphones). Such is the modern student today, and this new academic environment can be used to enhance student motivation, participation, and engagement by introducing similar multimedia-based activities in novel educational tools as part of the learning process.

The success of Multimedia Enhanced Learning (MEL) is fostering the creation of new educational resources and changing the learning paradigm as it impacts the roles between teachers and students as well as in the way teachers manage the processing of knowledge to their students' optimal benefit. The development of MEL tools is continuously increasing, however stakeholders are not capitalizing on its potential to offer different and improved ways to disseminate and acquire, to evaluate what has been acquired, and to assimilate knowledge.

In an attempt to understand student's experience using elearning environments in general, and online multimedia tools in particular (a subset of elearning), most researchers so far have approximated and directly mapped the methods used in conventional environments and traditional media. These conventional/traditional methods had little explanation powers, as they do not capitalize on the potential of information web-based technologies. However, few researchers have considered new aspects and pedagogies more suitable for the virtual environment (Esteban-Millat, Martinez-Lopez, HuertasGarcia, Meseguer, \& Rodriguez-Ardura, 2014; Rushby, 2013).

A particular theory (and the interest of our study) suitable to explain student's experiences in elearning (virtual environments) is the concept of flow (Esteban-Millat et al., 2014; Mahnke, 2014; Saade \& Bahli, 2005, Saade, Elgaly \& Nebebe, 2011). The theory of flow developed by Csikszentmihalyi (1990) is defined as the holistic experience that people feel when they act with total involvement. Flow is a state where individuals are so absorbed in an activity that they experience narrowed awareness, are less self-conscious, and feel in control of their environment. Esteban-Millat et al. (2013) provide an in-depth analysis of flow in the virtual educational environments. Their work suggests the need to optimize the interface navigational characteristics leading to an enhanced online educational experience observed by such behavior as student's increase in usage time of online sessions.

In the same vein, this paper examines the role of flow in an elearning context and its impact on performance (a measure that is rarely reported). To that effect, we describe an in-house developed MEL tool and propose and test an experience-performance model, which is then assessed. The main results are presented and the most important challenges set out. The paper is organized as follows: In the next section, the research model provides a background of related work in the area of elearning, multimedia and assessment. The third section presents the methodology used here, and specifies the MEL tool, its requirements, and challenges. The fourth section presents the empirical evidence and the assessment of the proposed model. Finally in the fifth section, we discuss the results into context followed by conclusions and future work.

\section{RESEARCH MODEL}

Multimedia, in general, has the potential to support student's motivation and engagement across various contexts. Studies have reported on multimedia's support to intrinsic and extrinsic motivations (Saadé, 2007; Saadé, He \& Kira., 2007). Motivation in the context of IT adoption and use has been studied in terms of perceptions and beliefs. For example, perceived usefulness of a multimedia application is viewed as extrinsic motivation, and perceived ease of use of a multimedia application can be considered as intrinsic motivation; both determining attitudes and intentions. Additionally, the study 
of multimedia use for learning is similar to game-based learning and manifests the same features of flow (Huang, Johnson, \& Han, 2013).

\section{PERCEPTIONS}

Student's intention to use learning-related application has been studied in Technology Adoption/Acceptance/Satisfaction research. It has been tested in many contexts and various target technologies, including (to a lesser extent) multimedia and elearning (Toloun \& Hadidi, 2014).

Our research is anchored in the Theory of Reasoned Action (TRA) (Fishbein \& Azjen, 1975). The TRA explains the motivational structures towards a behavior based on attitudes toward that behavior and its influence on intentions. In addition to the TRA, we utilize the following four constructs (Davis, 1989): Perceived Ease of Use (PEU), Perceived Usefulness (PU), Attitudes (ATT) and intentions (INT). We posit that PEU and PU are antecedents of student's attitudes and consequently intention to use a MEL technology. PEU can be defined as the amount of cognitive effort that a student believes is required to successfully use the MEL tool. PU is the benefit (an extrinsic motivation) returned through the use of the MEL tool.

Attitude was included in the original TAM but was removed because it was believed to be an invalid affecter of INT. However, this was challenged in the context of elearning, where attitude was found to be an important moderator/mediator. Subsequent studies have shown that in some situations, particularly those with multimedia content, ATT can sufficiently influence INT (Saade \& Galloway, 2005).

Our construct formulation was extended to include cognitive absorption (CA). We include CA as a flow variable because PEU, PU and ATT do not sufficiently represent the multimedia context for learning (Saadé \& Bahli, 2005).

\section{COGNITIVE ABSORPTION}

Cognitive absorption is an appropriate addition to insure that the entertainment benefits of multimedia applications were taken into account. The factors that measure CA are focused immersion (FI), control (CON), curiosity (CUR), temporal dissociation (TD) and heightened enjoyment (HE) (Agarwal \& Karahanna, 2000). A similar structure has been used to measure the usage of video games (Hsu \& Lu, 2004), adoption of interactive technologies in hotels (Zhu \& Morosan, 2014), problematic internet use (Bozoglan, Demirer, \& Sahin, 2014), role of social presence (Leong, 2011), and in other contexts in healthcare, information systems, and other disciplines.

The CA variables represent one form or another of intrinsic motivation, where "a behavior is performed for itself, in order to experience pleasure and satisfaction inherent in the activity" (Vallerand, 1997). The theoretical basis derives primarily from the theory of flow developed by (Csikszemtmihalyi, 1990) which describes "the state in which people are so involved in an activity that nothing else seems to matter." This is characterized by the individual being engulfed with a sense of intense concentration, a feeling of being in total control of what he/she is doing, a loss of consciousness and an experience of time loss (Saadé \& Bahli, 2005).

Performance was added to this model as an outcome variable, in order to see the direct and indirect effects of beliefs and attitudes on the student's grade - a variable that has rarely been studied. This construct measures the actual performance of student's assessment after using the MEL online tool.

Based on the factors identified above and the theoretical basis, we propose the following hypotheses, as shown in Figure 1:

H1. Intention to use MEL tool will have a positive effect on Student's Performance.

H2. Perceived Usefulness of the MEL tool will have a positive relationship with Student's Performance. 
H3. Attitude will have a positive relationship with Intention to Use the MEL tool.

H4. Perceived Usefulness will have a positive relationship with Attitude towards the MEL tool.

H5. Perceived Ease of Use will have a positive relationship with Attitude towards the MEL tool.

H6. Perceived Ease of Use will have a positive relationship with Perceived Usefulness of the MEL tool.

H7. Cognitive Absorption will have a positive relationship with Perceived Ease of Use of the MEL tool.

H8. Cognitive Absorption will have a positive relationship with Perceived Usefulness of the MEL tool.

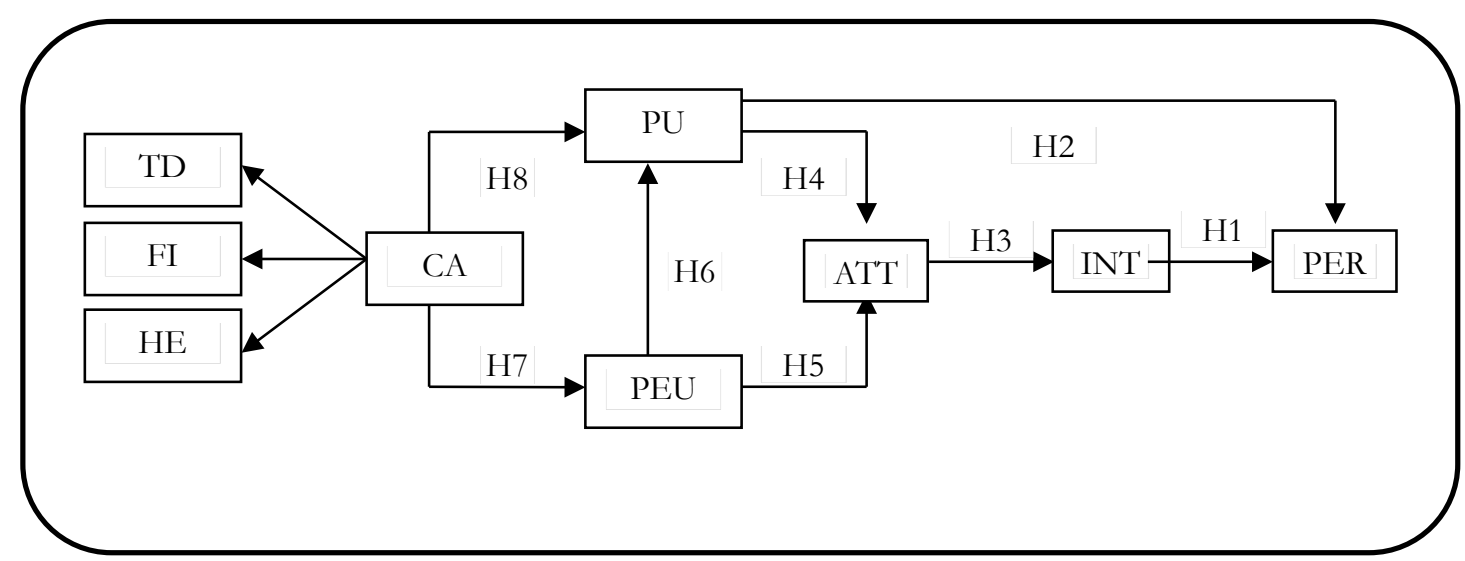

Figure 1. Proposed research Model.

\section{METHODOLOGY}

\section{CONTEXT}

This study was performed using usable responses collected from 93 students. These respondents are students at the John Molson School of Business. Surveys were voluntarily completed after the final exam of an introductory course in 'management information systems'. This was done at the end of two sequential semesters. Performance measurement is based on the student's actual grade achieved during the final exam. The section on the exam used to measure student's performance gave the students a short paragraph describing a business situation. Using this paragraph the students could derive entities, attributes, relationships, and cardinalities. The students were then asked to create a simplified Entity Relationship Diagram (ERD) diagram.

\section{THE MULTIMEDIA TOOL}

The tutoring system is a web-based application that manages the knowledge of ERD taught in an introductory management class and presents it to the student in an interactive and game fashion. ERD design is a logical planning step in database management involving the creation of graphical representations of relationships between information of interest to the organizations, otherwise known as entities. The rules of the game entail the ERD's design elements (entity, relationships, and cardinalities). Interactivity with the MEL was observed to have many similarities with video games. The effects of cognitive absorption include full involvement solely due to the task at hand, heightened satisfaction of the task, temporal dissociation and stronger beliefs toward user control (Hedman \& Parvaneh, 2004). 
The MEL tool has two major procedures. The first is a text and animation based tutorial. This presentation describes the necessary tools and the rules, which govern the design of relationship diagrams. The second part of the MEL tool is an ERD problem practice section. In this section the user can build ERD's using a system that is similar to a CASE tool.

From the start, students are offered an option between viewing the animated presentation or completing the practice problems. Should the students choose to watch the presentation then they follow a step-by-step presentation. When the student is ready, then they can request to play the interactive game to practice the building of the ERD.

In the problem space, the learner is given a problem statement, a set of ERD symbols, a whiteboard to combine the ERD pieces together using the mouse by dragging and dropping the ERD symbols, and a function toolbar. This toolbar contains three options: to skip to the next problem, hint, and help. Initially the hint and help functions are inactive. Additionally there is a text box showing the score, which starts at one hundred. If the learner places an ERD symbol in the wrong place or in the wrong order, ten points are removed from the score. Should the students score fall to 70 , the hint button becomes activated. If the student needs a hint they may now press this button and will be given a short animated presentation. The hint will be presented similarly to the slide presentation section but will have a presentation specific to the section of the problem the student is working on currently. Should the learners score fall to fifty they are offered the help button. This button, if pushed, solves the problem in the same style animation as the slide presentation.

\section{INSTRUMENT \& PROCESS}

Items (presented in Table 1) were used for the survey. The constructs and items were adopted from validated prior research work. In this study, the items were validated in a pilot study and some wording was changed to account for the context of using MEL tool. All items were measured using a fivepoint Likert-type scale with anchors from "Strongly Disagree" to "Strongly Agree". The survey included items worded with proper negation and a shuffle of the items to reduce monotony of questions measuring the same construct.

Table 1. Question items used in the study.

\begin{tabular}{|l|l|l|}
\hline \multicolumn{2}{|c|}{ Construct } & Item \\
\hline $\begin{array}{l}\text { Perceived } \\
\text { Usefulness } \\
\text { (PU) }\end{array}$ & PU1 & Learning to navigate the MEL is easy for me. \\
\hline \multirow{2}{*}{$\begin{array}{l}\text { Perceived } \\
\text { Ease of Use } \\
\text { (PEU) }\end{array}$} & PEU1 & $\begin{array}{l}\text { I feel that using the MEL has improved my performance in the } \\
\text { Comm301 course. }\end{array}$ \\
\cline { 2 - 4 } & PU3 & It was easy for me to become skillful at using the MEL. \\
\hline \multirow{2}{*}{$\begin{array}{l}\text { PU4 } \\
\text { I find the MEL easy to use. }\end{array}$} \\
\cline { 2 - 4 } & PEU3 & $\begin{array}{l}\text { Using the MMLS has enhanced my effectiveness in the comm301 } \\
\text { course. }\end{array}$ \\
\cline { 2 - 4 } & PEU4 & I find the MEL useful in the comm301 program. \\
\hline $\begin{array}{l}\text { Attitude } \\
\text { (ATT) }\end{array}$ & ATT1 & Using MEL in the Comm301 course was a good idea. \\
\hline
\end{tabular}




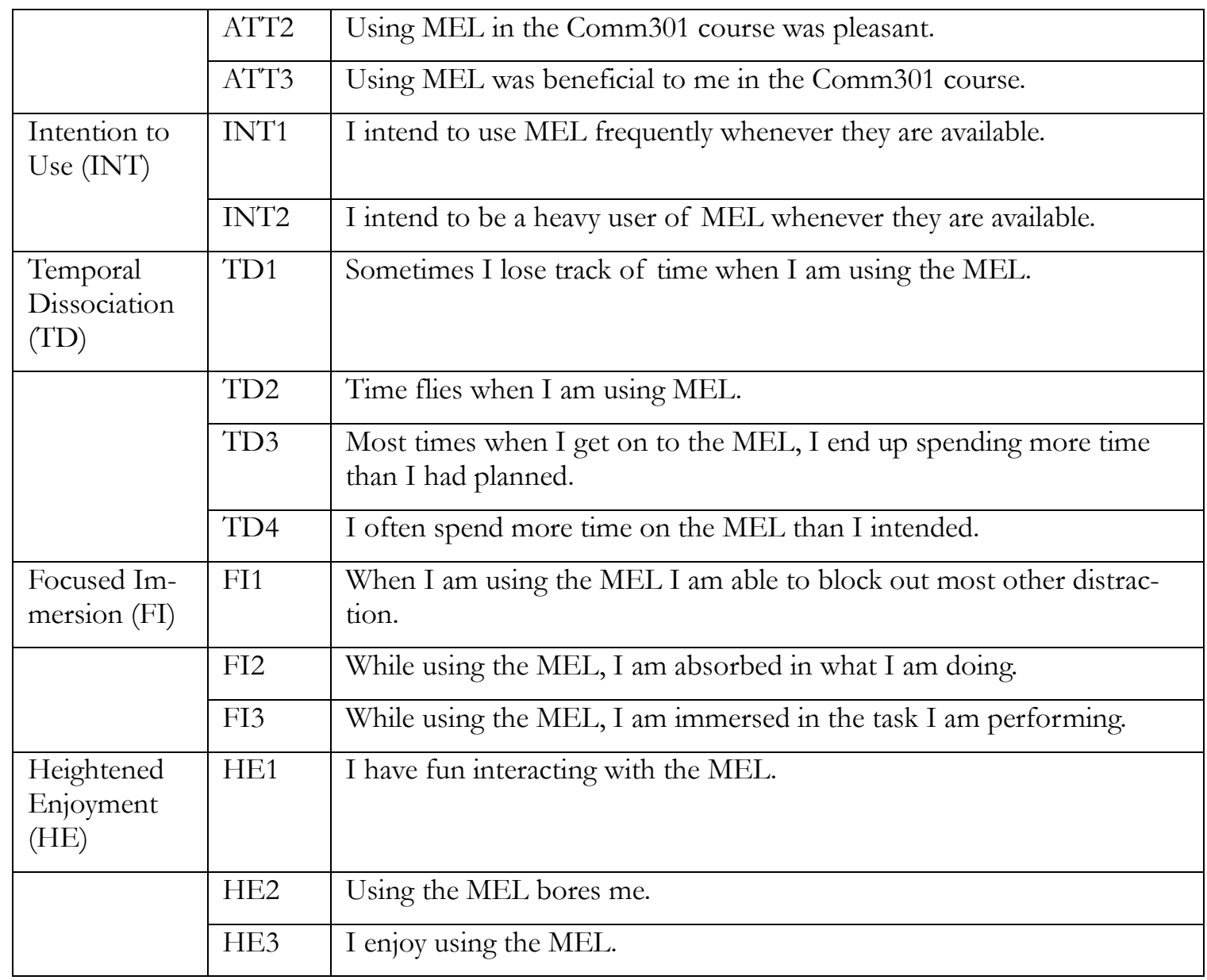

\section{RESULTS AND DISCUSSION}

Table 2 displays the descriptive statistics of the constructs used in this study. Included in this table are the number of items used for each construct/factor and the calculated Rho values needed to assess the reliability of the latent variables. As shown in Table 2, the calculation of Rho for each of the factors used is significantly greater than the acceptable limit of 0.5 (Saadé \& Bahli, 2005).

Table 2: Descriptive Statistics.

\begin{tabular}{|l|c|c|c|c|}
\multicolumn{1}{c}{} & \multicolumn{1}{c}{ \# Items } & \multicolumn{1}{c}{ Mean } & \multicolumn{1}{c|}{ St Dev } & Rho \\
\hline PU & 4 & 3.28 & 1.08 & 0.735 \\
\hline PEU & 4 & 3.24 & 1.04 & 0.757 \\
\hline INT & 2 & 3.37 & 1.10 & 0.401 \\
\hline ATT & 3 & 3.68 & 1.13 & 0.735 \\
\hline CA & & 2.974 & 0.75 & 0.377 \\
\hline TD & 4 & 3.10 & 0.99 & \\
\hline FI & 3 & 3.05 & 0.93 & \\
\hline HE & 3 & 3.33 & 1.03 & \\
\hline
\end{tabular}


Based on the mean and standard deviations shown in Table 2, students felt neutral about the benefit of MEL (PU approximately 3) to their performance. It seems that it is the same outcome in relation to the ease of use of the MEL and their intentions to use it. Student's attitudes, however, were more in agreement that the MELs are a good idea. The average performance was close to $80 \%$, for those who used the MEL, which was significantly higher than students who did not use, by around $10 \%$. With respect to Rho, a value of 0.5 is usually set as the benchmark for reliability. All constructs attained the required benchmark except for CA and INT. Measurement model analysis was done next and discussed in the next section.

\section{MEASUREMENT MODEL}

In this section we present the results of the exploratory factor analysis (Table 3) and inter-construct correlations (Table 4). Varimax rotation was used to calculate the factor loadings. This type of analysis was performed to insure that all statements within the survey measure the desired variable. Factor loadings greater than 0.5 are considered acceptable. Based on this threshold, Table 3 shows that all items except INT load significantly higher than 0.5 with their related items than they do with items measuring other factors.

Table 3: Factor analysis results.

\begin{tabular}{|l|c|c|c|c|c|}
\hline $\begin{array}{l}\text { Scale } \\
\text { Items }\end{array}$ & \multicolumn{1}{c}{ INT } & \multicolumn{1}{c|}{ ATT } & \multicolumn{1}{c|}{ PU } & PEU & CA \\
\hline INT1 & $\mathbf{0 . 9 4 6 7}$ & 0.6077 & 0.4509 & 0.2638 & 0.3582 \\
\hline INT2 & $\mathbf{0 . 9 2 1 9}$ & 0.5091 & 0.3823 & 0.2307 & 0.3635 \\
\hline ATT1 & 0.5431 & $\mathbf{0 . 8 9 7 1}$ & 0.5296 & 0.4203 & 0.4557 \\
\hline ATT2 & 0.5108 & $\mathbf{0 . 8 8 3 1}$ & 0.5154 & 0.4323 & 0.4502 \\
\hline ATT3 & 0.5703 & $\mathbf{0 . 9 2 1 5}$ & 0.6301 & 0.4183 & 0.3876 \\
\hline PU1 & 0.3701 & 0.549 & $\mathbf{0 . 8 9 6 4}$ & 0.459 & 0.3581 \\
\hline PU2 & 0.45 & 0.5497 & $\mathbf{0 . 8 9 9 6}$ & 0.4526 & 0.4428 \\
\hline PU3 & 0.3901 & 0.547 & $\mathbf{0 . 9 2 1 2}$ & 0.4517 & 0.4176 \\
\hline PU4 & 0.4089 & 0.6024 & $\mathbf{0 . 8 8 7 8}$ & 0.4795 & 0.3983 \\
\hline PEU1 & 0.2372 & 0.397 & 0.4068 & $\mathbf{0 . 8 6 2 3}$ & 0.212 \\
\hline PEU2 & 0.2271 & 0.4053 & 0.4291 & $\mathbf{0 . 8 7 0 9}$ & 0.2644 \\
\hline PEU3 & 0.2377 & 0.4324 & 0.5157 & $\mathbf{0 . 9 1 0 1}$ & 0.3461 \\
\hline PEU4 & 0.2429 & 0.433 & 0.4595 & $\mathbf{0 . 9 0 4 2}$ & 0.323 \\
\hline TD & 0.2304 & 0.2412 & 0.2437 & 0.1309 & $\mathbf{0 . 6 6 1 6}$ \\
\hline FI & 0.2763 & 0.3272 & 0.2899 & 0.2618 & $\mathbf{0 . 7 3 5 8}$ \\
\hline HE & 0.3304 & 0.4439 & 0.4228 & 0.298 & $\mathbf{0 . 8 0 2 5}$ \\
\hline
\end{tabular}

The internal reliabilities assessed by composite reliability are greater than 0.70 (see Table 4), which is considered to be the acceptable threshold for adequate results. At the same time, we present the Cronbach Alpha for all constructs, which are also acceptable at values higher than 0.8. 
Table 4: Inter-construct correlations.

\begin{tabular}{|c|c|c|c|c|c|c|c|}
\hline $\begin{array}{c}\text { Composite } \\
\text { Reliability } \\
\text { (\# of } \\
\text { item) } \\
0.93\end{array}$ & $\begin{array}{c}\text { Cronbach } \\
\text { Alpha }\end{array}$ & INT & ATT & PU & PEU & CA \\
\hline & 0.85 & $\mathbf{0 . 9 3}$ & & & & \\
\hline & 0.93 & 0.88 & 0.60 & $\mathbf{0 . 9 0}$ & & & \\
\hline 0.94 & 0.92 & 0.45 & 0.62 & $\mathbf{0 . 9 0}$ & & \\
\hline & 0.94 & 0.91 & 0.27 & 0.47 & 0.51 & $\mathbf{0 . 8 9}$ & \\
\hline & 0.78 & 0.57 & 0.39 & 0.48 & 0.45 & 0.33 & $\mathbf{0 . 7 3}$ \\
\hline $\begin{array}{l}\text { The numbers on the leading diagonal are the square root of the variance shared between } \\
\text { the constructs and their measures. Off diagonal elements are the correlations among } \\
\text { constructs. For discriminant validity, diagonal elements should be larger than off- } \\
\text { diagonal elements. }\end{array}$
\end{tabular}

The results of factor analysis and composite reliabilities demonstrate overall satisfactory convergent and discriminant validity of the measures. Table 3 also shows that some ATT, PU, and INT cross loadings are slightly above 0.5 which can be interpreted as two constructs measuring similar beliefs and perceptions. This may be due to the way that the multimedia tool was integrated into the course requirements. Students were provided this MEL tool as a resource. Its usage was voluntary. In the course outline, it was mentioned that one of 4 parts of the final exam will entail a question on the concept of ERDs and that this tool will help them learn it better. Therefore, students may or may not have used it; some may have used it very little and others a lot; and some students used it with attention (in other words by carefully manipulating the ERD symbols and putting serious thought into their decisions to construct the ERD); while others just clicked back and forth until they got the right answer. This varied way in which students may have used the MEL tool may explain why the factor cross-loadings were not as desired. Therefore, student's responses to the MEL tool's usefulness are a reflection of their intentions and to a larger extent even, that of their attitude. This is also evident in Table 4 where the inter-construct correlations for INT, ATT, and PU are so close (around $0.90)$ and that of CA (0.73) is significantly different. Nevertheless, although these results are not as desired, they are still acceptable. We continue in the next section, with structural equation modeling of the research model proposed above.

\section{STRUCTURAL EQUATION MODELING}

The proposed model (Figure 1) was tested using structural equation modeling. Through this modeling we can determine the degree to which the proposed model explains the constructs selected using the collected data. This strength of support is referred to as the R-square value. R-squared is essentially the percentage of variance within the dependent construct that is explained by the preceding/independent constructs of the model. The R-squared values calculated in this research are shown within the construct box in Figure 2 below (e.g., INT/ 57 represents the construct Intentions $/ \mathrm{R}$-squared $=57 \%$ ). The path coefficients are also show on the paths in this diagram representing the hypotheses stated above. The path coefficients represent the strength of the relationship between the dependent and independent variables.

The R-squared values of PU and INT are 46\% and 57\%, respectively, indicating relatively strong values for the variance explained. PEU, ATT and PER have lower R-squared values, where PEU is 0.16, ATT is 0.16 and PER is 6 , which is the lowest. These results means that the proposed model ac- 
counts for $57 \%$ of variance of intentions. The path coefficients shown were all found to be significant at $<0.05$ except for the path lying between PEU and ATT. Due to the low R-squared value of PER it can be assumed that the model's ability to explain student's performance in the present context is not strong.

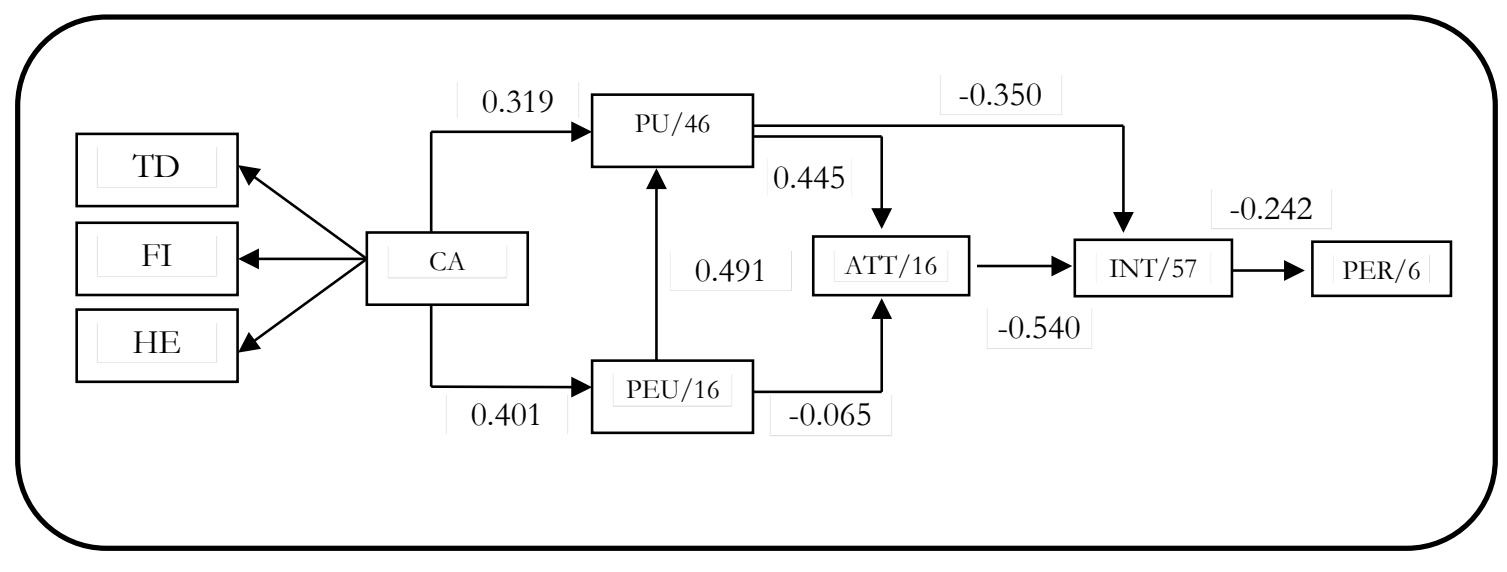

Figure 2. Propose research model results.

The model results clearly show strong and significant support to all hypotheses in terms of relationships (as indicated by the path coefficients - numbers on the arrows) with the exception of PEUATT, which is significant, but at a value of -0.065 (negligible). The strongest relationship is that of ATT-INT, which is -0.540 . This model results shows some interesting trend in that CA influences positively beliefs (PU and PEU) while beliefs (primarily PU and ATT) have a negative influence on INT, and in turn INT negatively influencing PER. This suggests that the more engaged (through the experience of flow as measured by CA) the student is while using the MEL tool, the stronger their beliefs in the ease of use and usefulness of the tool. However, contrary to what we would expect, when a student's belief in the usefulness of the MEL tool increases, their intentions to use it further decreases. This may be explained in terms of confidence in the knowledge gained. That is, as students continue to use the MEL tool, they gain confidence in the knowledge gained and tend to feel that using it further is less necessary. In other words, students who use the MEL tool more, intend to stop using it because probably they felt that they have achieved their goal of solving ERD problems (in this case). This is the effect observed from using the tool successfully. Following up on this trend to the INT-PER relationship, we find out that students who intend to use it more perform less, or put differently, students who intend to use it less perform better. This actually supports the rationalization that preceded it in the PU-INT relationship, and goes as follows: student who use the MEL more have less intentions to use it further THAN students who have less intentions to use it further (as a result of using the MEL enough to have learned all that it has to offer) perform better. This conclusion is a great insight to how multimedia can be integrated into pedagogy.

Due to the weak explanation capability of PER in the model, we pressed our investigation further to explore any other possibilities. In order to investigate any relationship that may exist between the constructs and performance we performed regression analysis of all the constructs with PER, one by one. The results are shown in Table 5 where the path coefficients and the R-squared values are presented. All results have a significance level of $<0.05$. As can be seen from the Table 5, PU and INT have the highest direct effect on PER as compared to the other constructs. The direct relationship of PEU to PER resulted in an R-squared of close to 3\%. PER explains CA by only $0.1 \%$ of the variance while ATT is explained by only $0.3 \%$. Needless to say, that these results are symptomatic of the integration of the MEL tool into the pedagogy and assessment of the course. This will be further discussed in the conclusion section. 
Table 5: Regression of all constructs with PER.

\begin{tabular}{|l|c|c|}
\hline Relationship & Path & R-squared (\%) \\
\hline PU - PER & 0.243 & 6 \\
\hline PEU - PER & -0.185 & 3 \\
\hline INT - PER & -0.246 & 6 \\
\hline CA - PER & 0.022 & 0.1 \\
\hline AT'T - PER & -0.052 & 0.3 \\
\hline
\end{tabular}

The results so far have provided us with an insight to possible weakness in the implementation of the MEL tool in our course. Consequently and at this point in our research investigation, we felt that there remains one question which would confirm and further strengthen the outcome of those previous results or provide a more appropriate model to explain our research. We question the influence of INT on the entire model. Theory tells us that attitudes shape intentions, which in turn impact action. This question was addressed by Fishbein and Azjen (1975) and later by Davis (1986) in the context of information technology satisfaction. Since then, many studies under a wide range of contexts were published by removing the AT'T construct, with mixed results. However, none tested the direct influence of ATT on actual use or performance in our context.

To that effect, a modification of the model in Figure 1 is proposed by removing INT based on the assumption of existence of a possible variable such as effort between ATT and PER. The constructs of the new model were then tested for discriminant and convergent validity using factor analysis ( $\mathrm{Ta}$ ble 6). The results of the factor analysis for the new model show that all factors do have the prescribed validity and that the issue of multiple loadings seem to been caused by INT as the factor loading results are what we would expect them to be.

Table 6: Factor analysis of Model without INT.

\begin{tabular}{l|c|c|c|c|}
\multicolumn{1}{l}{} & \multicolumn{1}{c}{ PU } & \multicolumn{1}{c}{ ATT } & PEU & CA \\
PU1 & $\mathbf{0 . 7 7 1}$ & 0.250 & 0.198 & 0.170 \\
\cline { 2 - 5 } PU2 & $\mathbf{0 . 8 6 2}$ & 0.169 & 0.213 & 0.104 \\
PU3 & $\mathbf{0 . 7 7 9}$ & 0.185 & 0.355 & 0.275 \\
PU4 & $\mathbf{0 . 7 3 9}$ & 0.236 & 0.290 & 0.143 \\
PEU1 & 0.427 & 0.094 & $\mathbf{0 . 7 2 6}$ & 0.021 \\
PEU2 & 0.202 & 0.191 & $\mathbf{0 . 6 6 1}$ & 0.342 \\
PEU3 & 0.009 & -0.039 & $\mathbf{0 . 6 3 0}$ & 0.083 \\
PEU4 & 0.407 & 0.012 & $\mathbf{0 . 8 6 9}$ & 0.097 \\
ATT1 & 0.110 & $\mathbf{0 . 9 5 5}$ & 0.076 & 0.092 \\
ATT2 & 0.239 & $\mathbf{0 . 8 7 7}$ & 0.036 & 0.078 \\
ATT3 & 0.144 & $\mathbf{0 . 9 5 2}$ & 0.020 & 0.097 \\
TD & 0.293 & 0.202 & 0.153 & $\mathbf{0 . 8 5 9}$ \\
FI & 0.293 & 0.202 & 0.153 & $\mathbf{0 . 9 0 1}$ \\
\hline HE & 0.293 & 0.202 & 0.153 & $\mathbf{0 . 8 7 8}$ \\
\hline
\end{tabular}


Saadé, Nebebe, \& Kira

\section{CONCLUSIONS}

The present study proposes a model to explain the use of multimedia enhanced learning tools in higher education. The context entails the subject matter of entity relationship diagrams as taught in a fundamental common course in a business school in Canada. The model draws on the theories of planned behavior and reasoned action and contributes to the body of knowledge in the extension of these theories to the use of multimedia of enhanced learning, the integration of cognitive absorption in the research model, and the impact of the model on performance (which is a unique contribution to research since we have not found any research work published on the integration of performance in an empirical study).

The results of this study provide a number of interesting insights to the use of multimedia enhanced learning tools: (1) Cognitive absorption (CA) was shown to be a significant antecedent to beliefs in the Multimedia Enhanced Learning (MEL) context; (2) Intention (INT) plays an important moderating role in the support of the model hypotheses; (3) the model without the INT construct provides better psychometric properties of the model; (4) PU influences INT contrary to what we would expect, however, in the context of MEL tool, the results are true to student's experiences in the learning context; (5) following (4), the negative influence of INT on PER further supports student's learning experience; (6) students who used the MEL tool performed around 13\% better from those who did not use it; and (7) all possible investigation into PER explanation rendered weak results, alluding to the need to identify and explore other constructs to fill the gap between INT and PER. What do those results imply to the practitioner? We think of the practitioner herein as the teacher and designer of the course and MEL tool, and as such, we attempt to connect the implications of the results to the practitioner's role. First, it is clear (although more refinement to the research is needed) and accepted that multimedia has the strong potential to enhance the student's learning experience. Due to the nature of the multimedia technologies, a strong design focus may be achieved to considering the integration of multimedia elements that foster the creation of flow. Flow can then be measured by the CA construct as shown in this study. The introduction of flow in the MEL tool can be done by mapping elements of game and process. This high-level design considerations are to be implemented to specific parts of the subject matter and those that benefit from multimedia need to be identified by the practitioner. Therefore, the practitioner needs to identify the specific subject matter in the course that benefits from multimedia, create the game environment for that subject matter, and establish a process, which clearly tells the student that they have achieved their learning goals. At the course level, this implies that the more MELs there are in the course, the higher overall grade a student would be able to achieve. This value that multimedia provides to the student's learning experience is the foundational proposition to the authors dream: every student can achieve the highest possible grade.

In our follow-up research, attention will focus towards the gap between intentions and performance, in particular, what we missed, and what should be studied to enhance the explanation power of performance.

\section{REFERENCES}

Agarwal, R. \& Karahanna, E. (2000). Time flies when you're having fun: Cognitive absorption and beliefs about information technology usage. MIS Quarterly, 24(4), 665-694. https://doi.org/10.2307/3250951

Bozoglan, B., Demirer, V., \& Sahin, I. (2014). Problematic internet use: Functions of use, cognitive absorption and depression. Computers in Human Behavior, 37, 117-123. https://doi.org/10.1016/j.chb.2014.04.042

Cheung, M. K. C., Pui-Yee, C., \& Lee, K. O. M. (2011). Online social networks: Why do students use facebook? Computers in Human Behavior, 27(4), 1337-1343. https://doi.org/10.1016/i.chb.2010.07.028

Csikszentmihalyi, M. (1990). Finding flow: The psychology of optimal experience. New York: Harper Perennial. 
Explaining Performance Using a Multi-Media Tool

Davis, F.D. (1989). Perceived usefulness, perceived ease of use, and user acceptance of information technology. Management Information Systems Quarterly, 13, 319-339. https://doi.org/10.2307/249008

Esteban-Millat, I., Martinez-Lopez, J. F., Huertas-Garcia, R., Meseguer, A., \& Rodriguez-Ardura, I. (2104). Modelling students' flow experiences in an online learning environment. Computers \& Education, 71, 111123. https://doi.org/10.1016/j.compedu.2013.09.012

Fishbein, M., \& Ajzen, I. (1975). Belief, attitude, and behavior: An introduction to theory and research. Reading, Mass.: Addison Wessley.

Hedman, L., \& Parvaneh, S. (2004). Using information technology: Engagement modes, flow experience, and personality orientations. Behaviour and Information Technology, 23(2), 137-146. https://doi.org/10.1080/01449290310001648251

Hsu, C. \& Lu, H. (2004). Why do people play on-line games? An extended TAM with social influences and flow experience. Information and Management, 41, 853-868. https://doi.org/10.1016/i.im.2003.08.014

Huang, D. W., Johnson, E. T., \& Han, S. C. (2013). Impact of online instructional game features on college students' perceived motivational support and cognitive investment: A structural equation modeling study. The Internet and Higher Education, 17, 58-68. https://doi.org/10.1016/j.iheduc.2012.11.004

Leong, P. (2011). Role of social presence and cognitive absorption in online learning environments, Distance Education, 32(1), 5-28. https://doi.org/10.1080/01587919.2011.565495

Mahnke, R. (2014). Designing flow experience on the Web: A grounded theory of online shopping flow. 47th Hawaii International Conference on System Science, 3015-3024. https://doi.org/10.1109/hicss.2014.376

Morin, D., Thomas, J. D. E., Saadé, R. G. (2014). Problem-solving and web-based learning. Proceedings of the e-Skills for Knowledge Production and Innovation Conference 2014, Cape Town, South Africa, 243-253. Retrieved from http://proceedings.e-skillsconference.org/2014/e-skills243-253Morin797.pdf

Rushby, N. (2013). The future of learning technology: Some tentative predictions. Educational Technology and Society, 16(2), 52-58.

Saadé, G. R. (2007). Dimension of perceived usefulness: Towards enhanced assessment. Decision Science Journal of Innovative Education, 5(2), 289-310. https://doi.org/10.1111/j.1540-4609.2007.00142.x

Saadé, R., \& Bahli, B. (2005). The impact of cognitive absorption on perceived usefulness and perceived ease of use in online learning: An extension of the technology acceptance model. Information and Management, 42, 317-327. https://doi.org/10.1016/j.im.2003.12.013

Saadé, G. R., Elgaly, S., \& Nebebe, F. (2011). Examining a flow-usage model to understand multimedia-based learning. Interdisciplinary journal of Information, Knowledge, and Management, 6, 231-243. https://doi.org/10.28945/1495

Saadé, R. G., \& Galloway, I. (2005). Understanding intention to use multimedia information systems for learning. Informing Science: International Journal of an Emerging Transdiscipline, 2, 287-296. https://doi.org/10.28945/828

Saadé, G. R., He, X., \& Kira, D. (2007). Exploring dimensions to online learning. Computers in Human Behavior, 23(4), 1721-1739. https://doi.org/10.1016/j.chb.2005.10.002

Srivastava, S. (2012). A study of multimedia and its impact on students' attitude. IEEE International Conference on Technology Enhanced Education, 1-5.

Teo, B. S. P., \& Tse-Kian, N. (2006). Innovative teaching: Using multimedia to engage students in interactive learning in higher education. $7^{\text {th }}$ International Conference on Information Technology Based Higher Education and Training, 329-337. https://doi.org/10.1109/ithet.2006.339782

Vallerand, R. J. (1997). Towards a hierarchical model of intrinsic and extrinsic motivation. Advances in Experimental Social Psychology, 29, 271-374. https://doi.org/10.1016/s0065-2601(08)60019-2

Zhu, W. W., \& Morosan, C. (2014). An empirical examination of guests' adoption of interactive mobile technologies in hotels: Revisiting cognitive absorption, playfulness, and security. Journal of Hospitality and Tourism Technology, 5(1), 78-94. https://doi.org/10.1108/jhtt-09-2013-0029 


\section{BIOGRAPHY}
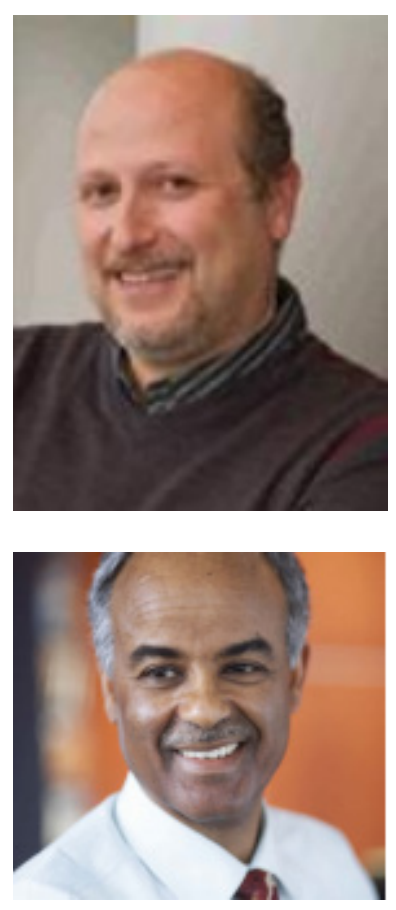

of SSENA (1999-2002).

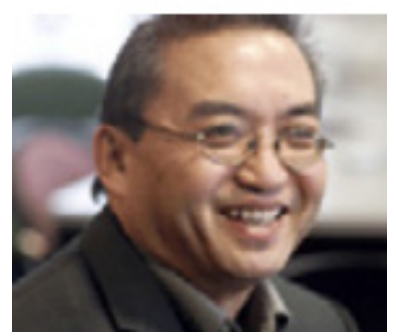

Dr. Dennis Kira is a professor at the Department of Supply Chain and Business Technology Management, John Molson School of Business, Concordia University, Canada. He has been with the schoole since 1983. He obtained his Ph.D. from University of British Columbia. Dr. Kira teaches System design, decision support systems, data management, data mining, Internet related programming, and e-commerce His research activities include Ecommerce, web design, distance learning, decision making under uncertainty, neural networks, machine learning, and financial modeling. Dr. Kira has published in IEEE, ORQ and management science among other journals. 